\title{
STUDI EVALUASI DAN PERENCANAAN SISTEM JARINGAN DRAINASE KECAMATAN ROGOJAMPI KABUPATEN BANYUWANGI
}

\author{
Muamar Khadafi', Ernawan Setyono ${ }^{2}$ \\ ${ }^{1 \& 2}$ Jurusan Teknik Sipil Fakultas Teknik - Universitas Muhammadiyah Malang \\ Alamat korespondensi : Jalan Raya Tlogomas 246 Malang 65144
}

\begin{abstract}
Parts of the eastern part of the island of Java there is a district in the district called banyuwangi. The condition of the existing drainage system in the sub-district Rogojampi banyuwangi can say is inadequate to accommodate the construction of both the discharge flow from the waste comes from household or storm water discharge exists as hydrological impacts that occur in the region. As a result, many districts Rogojampi often encounter serious problems due to standing water is often the case in several sections of the area especially during the rainy season arrives. So it is important to evaluate the channel capacity and planning of the new drainage system. Based on the evaluation results can be known that there are several sections of the channel were not able to hold back the flood discharge stage biennial (two-year Q), so that the necessary re-planning the channel cross section. It provides a new drainage plan is also required to reduce the pool of water when it rains. It also required some supporting buildings culvert drainage system to minimize area genagnan
\end{abstract}

Key Word ; Drainage, Discharge, Normalisation, Planing, Evaluation

\begin{abstract}
Abstrak
Pada bagian paling timur Pulau Jawa terdapat salah satu kabupaten yang disebut Kabupaten Banyuwangi. Kondisi sistem drainase yang ada di kecamatan Rogojampi Banyuwangi yang dapat katakan tidak memadai untuk mengakomodasi pembangunan kedua aliran debit dari limbah berasal dari debit air rumah tangga atau air hujan sehingga berdampak pada sistem hidrologi pada wilayah tersebut. Akibatnya, banyak kabupaten Rogojampi sering menghadapi masalah serius karena genangan air yang sering terjadi di beberapa bagian wilayah terutama selama musim hujan tiba. Jadi, penting untuk mengevaluasi kapasitas saluran dan perencanaan sistem drainase baru. Berdasarkan hasil evaluasi dapat diketahui bahwa ada beberapa bagian dari saluran tidak mampu menahan tahap dua tahunan debit banjir (dua tahun Q), sehingga diperlukan re-perencanaan bagian saluran lintas. Ini memberikan rencana drainase baru juga diperlukan untuk mengurangi genangan air saat hujan. Hal ini juga diperlukan beberapa pendukung sistem bangunan gorong-gorong drainase untuk meminimalkan genagnan daerah
\end{abstract}

Kata Kunci; Drainase, Pelepasan, Normalisasi, Perencanaan, Evaluasi

\section{PENDAHULUAN}

Bagian wilayah pulau jawa bagian timur terdapat sebuah kabupaten yang di namakan Kabupaten Banyuwangi. Perkembangan pembangunan kabupaten banyuwangi dapat di bilang cukup pesat.di lihat dari bertambahnya insprastruktur yang ada.tetapi semakin banyak insprastruktur yang ada maka semakin banyak juga masalah-masalah yang ada,terutama masalah banjir. Kondisi sistem drainase yang ada pada kecamatan rogojampi kabupaten banyuwaangi dapat dikatakan kurang memadai dalam menampung debit pembuangan baik debit yang berasal dari limbah buangan rumah tangga ataupun berasal dari debit air hujan yang ada sebagai dampak hidrologi yang terjedi pada wilayah tersebut.

Akibatnya kecamatan rogojampi kabupaten banyuwangi mengalami masalah yang cukup serius akibat genangan air yang sering terjadi di beberapa ruas wilayah terlebih pada saat musim penghujan tiba. Sehingga diperlukan evaluasi dan perencanaan ulang system drainase yang dapat mengurangi area genangan di kecamatan rogojampi kabupaten banyuwangi

Semakin bertambahnya jumlah penduduk, kurangnya kesadaran masyarakat akan pentingnya pemeliharaan saluran drainase, dan semakin berkurangnya lahan terbuka karena semakin 
majunya pembangunan kota menjadi salah satu faktor yang juga semakin memperparah keadaan genangan yang terjadi.

Selain hal tersebut diatas, faktor-faktor lain yang dapat menyebabkan terjadinya genangan air diperkirakan yaitu:

- Perencanaan drainase yang ada kurang memadai pada saat ini seiring dengan perkembangan pembangunan didaerah.

- Faktor kurangnya pemeliharaan drainase yang ada.

- Sebagian lokasi saluran drainase terputus-putus dan belum ada gorong-gorong yang memotong jalan atau pintu-pintu masuk dari pemukiman penduduk.

- Saluran air yang ada tidak sampai pada saluran pembuangan air (rawa atau sungai).

Dari faktor-faktor yang telah disebutkan diatas maka dapat diambil beberapa rumusan masalah, antara lain:

- Berapakah besar curah hujan rancangan kala ulang 2 tahun yang dihitung dengan menggunakan metode log pearson type III ?

- Berapakah besar debit banjir rancangan terbesar kala ulang 2 tahun?

- Berapakah jumlah ruas saluran yang perlu dinormalisasi dan direncanakan ulang dimensinya?

Batasan masalah yang diambil dalam melakukan studi ini adalah sebagai berikut:

- Daerah studi penelitian yang diambil adalah kecamatan rogojampi kabupaten .

- Perencanaan dan perhitungan jumlah air buangan penduduk dan besarnya debit banjir rancangan yang terjadi pada daerah studi menggunakan periode ulang 2 tahun.

- Menganalisa dimensi dan kapasitas saluran drainase yang ada pada saat ini dalam memenuhi kebutuhan debit buangan yang terjadi pada wilayah penelitian.

- Tidak membahas mengenai hidrolik sungai.

- Mengevaluasi saluran drainase yang mengalami genangan saat ini.

- Tidak membahas analisa biaya.

- Tidak membahas Transportasi sediment
Maksud dari studi adalah menganalisa besarnya debit pembuangan dari sarana drainase yang ada pada wilayah penelitian, kemudian merencanakan sistem drainase yang tepat dan efiesien sehingga mengurangi jumlah genangan air yang sering terjadi.

Tujuan dari studi ini adalah memberikan sumbangan pemikiran bagi pemerintah setempat yang berwenang dalam bidang ini untuk perencanaan perbaikan saluran drainase pada masa yang akan datang.

\section{METODE PENELITIAN}

\section{Distribusi Log Pearson Type III}

Setelah diketahui tinggi curah hujan harian maksimum dari data hujan yang diperoleh, maka dengan menggunakan metode ini dapat dihitung besarnya hujan rencana yang terjadi dengan periode ulang $\mathrm{T}$ tahun.

- Menghitung harga rata rata

- Menghitung harga standart deviasi

- Menghitung kepencengan

- Mnghiting anti log dari log Qt untuk menghitung curah hujan rencana kala ulang $t$ tahun

\section{Uji Kesesuaian}

Untuk mengetahui apakah suatu data sesuai dengan jenis sebaran teoritis yang dipilih, maka setelah penggambarannya pada kertas probabilitas perlu dilakukan pengujian lebih lanjut. Pengujian ini biasanya dengan uji kesesuaian (testing of goodness of fit) yang dilakukan dengan dua cara Uji Smirnov Kolmogorof dan Uji Chi-Square. Plotting data dilakukan dengan tahapan:

- Data curah hujan maksimum harian rata-rata tiap tahun disusun dari kecil ke besar.

- Hitung probabilitasnya

- Uji Smirlov Kolmogorov

- Uji Chi - SquareUji ini digunakan untuk menguji simpangan-simpangan secara vertikal

\section{Dasar Perhitungan Debit}

Untuk merencanakan dimensi saluran (drainase) perlu dilihat perhitungan jumalh air hujan secara maksimum. Dalam hal ini curah hujan yang dipakai kala ulang 2 tahun untuk tata guna lahan 
sebagai saluran utama dengan jenis saluran utma (Suhardjono, 1984 : 20) dan jumlah air kotor atau air buang rumah tangga yang melewati saluran tersebut.

\section{Debit Rencana}

Untuk menentukan banjir maksimum bagi saluran-saluran dengan aliran kecil, kira-kira 100200 acres (kira-kira 40-80 ha) digunakan rumus rasional

$$
Q=C \times I \times A
$$

Apabila digunakan rumus matrik, maka rumus rasional menjadi :

$$
\begin{aligned}
Q & =\frac{1}{3.6} \times C \times I \times A \\
& =0.278 \times C \times I \times A
\end{aligned}
$$

\section{Intensitas hujan}

Menurut Soemarto (1987), intensitas hujan adalah besarnya curah hujan rata-rata yang terjadi di suatu daerah dalam suatu satuan waktu tertentu yang sesuai dengan waktu konsentrasi dan periode ulang tertentu. Lama waktu konsentrasi untuk berbagai daerah berbeda-beda. Intensitas hujan merupakan suatu fungsi dari lama waktu curah hujannya.

$$
I=\frac{R_{24}}{24} \times\left(\frac{24}{T c}\right)^{\frac{2}{3}}
$$

Sedangkan waktu konsentrasi (tc) adalah waktu yang dibutuhkan oleh butiran air untuk bergerak dari titik yang terjauh pada daerah pengaliran sampai ke titik pembuangan. Salah satu metode untuk memperkirakan waktu konsentrasi adalah dengan menggunakan rumus:

(Suhardjono,1984)

$$
T c=T o+T d
$$

Sedangkan untuk mencari besar Td Dengan Cara-Coba Untuk mengontrol hasil di pakai rumus sebagai berikut:

$$
T d=\frac{L}{V}
$$

\section{Debit Air Kotor}

Debit air kotor adalah debit yang berasal dari air buangan hasil aktivitas penduduk yang berasal dari lingkungan rumah tinggal, instansi, bangunan komersial, dan lain sebagainya.

Dalam perencanaan, estimasi mengenai total aliran air buangan dibagi 3 (tiga) yaitu :

- $\quad$ Air buangan domestik

- Infiltrasi air permukaan (hujan) dan air tanah (pada daerah pelayanan dan sepanjang pipa).

- $\quad$ Air buangan industri dan komersial.

Rumus yang digunakan untuk debit air kotor adalah:

$\mathrm{Q}_{\text {domestik }}=\frac{P_{n} \times Q_{\text {kep. }}}{A}$

\section{Perhitungan Proyeksi Penduduk}

Perhitungan untuk mencari pertumbuhan jumlah penduduk sebagai berikut:

Metode yang digunakan adalah metode geometric :

$\mathrm{r}_{\text {rata-rata }=} \frac{r_{1}+r_{2}+r_{3}+r_{4}+r_{5}}{4}$

Analisa prediksi pertumbuhan penduduk sampai tahun rencana:

$\mathrm{P}_{\mathrm{n}}=\mathrm{P}_{\mathrm{o}} \times\left(1+\mathrm{r}_{\text {rata-rata }}\right)^{\mathrm{n}}$

Pertumbuhan penduduk eksponesial

$P_{n}=p_{0} \times e^{r \cdot n}$

\section{Dimensi Saluran Dranase}

Dimensi saluran drainase dihitung dengan pendekatan rumus-rumus aliran seragam, dan mempunyai sifat-sifat sebagai berikut :

- Dalam aliran, luas penampang lintang aliran, kecepatan aliran serta debit selalu tetap pada setiap penampang lintang.

- Garis energi dan dasar saluran selalu sejajar. 


\section{Kondisi Wilayah Studi}

Kondisi Sistem Drainase di kecamatan rogojampi kabupaten banyuwangi dapat dikatakan kurang memenuhi syarat terutama karena tersumbatnya saluran drainase oleh kotoran sampah. Ada beberapa tempat saluran yang sudah dibangun namun belum tersambung kearah pembuangan akhir sehingga menimbulkan kantong-kantong air jika terjadi hujan.

\section{Area Genagan}

Kejadian genangan air di suatu kawasan bisa diakibatkan oleh adanya hujan lokal dimana daerah tersebut merupakan cekungan sehingga air yang ada tidak bisa dialirkan secara langsung ke saluran drainase yang ada, saluran tidak bisa menampung aliran yang ada (penampangnya terlalu kecil), banyaknya sampah yang mengendap di saluran (saluran tidak pernah dibersihkan), atau sebagai akibat dari sistem yang ada di hilir (bak water atau air laut pasang).

\section{HASIL DAN PEMBAHASAAN}

\section{Uji Kesesuaian Distribusi Log Pearson Type III}

Seperti yang dijelaskan diatas bahwa uji kesesuaian distribusi frekwensi akan dilakukan pada distribusi Log-Pearson Type III dapat dilihat pada tabel 1.

Tabel 1. Uji Kesesuaian Distribusi Log Pearson Type III

\begin{tabular}{lcc}
\hline No & $\begin{array}{c}\text { Hujan } \\
\text { maximum } \\
(\mathrm{mm})\end{array}$ & $\mathrm{P}=\frac{m}{n+1} \times 100 \%$ \\
\hline 1 & 178 & 6.25 \\
2 & 166 & 12.5 \\
3 & 160 & 18.75 \\
4 & 125 & 25 \\
5 & 124 & 31.25 \\
6 & 122 & 37.5 \\
7 & 115 & 43.75 \\
8 & 115 & 50 \\
9 & 107 & 56.25 \\
10 & 100 & 62.5 \\
11 & 93 & 68.75 \\
12 & 71 & 75 \\
13 & 69 & 81.25 \\
14 & 69 & 87.5 \\
15 & 63 & 93.75 \\
\hline
\end{tabular}

Tabel 2. Curah hujan Rancangan dengan metode lo-pearson type III

\begin{tabular}{ccccccc}
\hline No & $\mathrm{Xi}$ & $\mathrm{P}(\%)$ & $\log \mathrm{Xi}$ & $(\log \mathrm{Xi}-\log \mathrm{X})$ & $(\log \mathrm{Xi}-\log \mathrm{X})^{2}$ & $(\log \mathrm{Xi}-\log \mathrm{X})^{3}$ \\
\hline 1 & 178 & 6.25 & 2,25042 & $-0,22383$ & 0,05009 & $-0,01121$ \\
2 & 166 & 12.5 & 2,22010 & $-0,19351$ & 0,03744 & $-0,00746$ \\
3 & 160 & 18.75 & 2,20412 & $-0,17753$ & 0,03151 & $-0,00559$ \\
4 & 125 & 25 & 2,09691 & $-0,07032$ & 0,00494 & $-0,00035$ \\
5 & 124 & 31.25 & 2,09342 & $-0,06683$ & 0,00446 & $-0,00030$ \\
6 & 122 & 37.5 & 2,08635 & $-0,05976$ & 0,00357 & $-0,00021$ \\
7 & 115 & 43.75 & 2,06069 & $-0,03410$ & 0,00116 & $-0,00004$ \\
8 & 115 & 50 & 2,06069 & $-0,03410$ & 0,00116 & $-0,00004$ \\
9 & 107 & 56.25 & 2,02938 & -0.00279 & 0,000008 & 0,000000021 \\
10 & 100 & 62.5 & 2,00000 & 0,02659 & 0,00071 & 0,000019 \\
11 & 93 & 68.75 & 1,96848 & 0,05811 & 0,003376 & 0,000196 \\
12 & 71 & 75 & 1,85125 & 0,17534 & 0,030744 & 0,00539 \\
13 & 69 & 81.25 & 1,83885 & 0,18774 & 0,03524 & 0,006617 \\
14 & 69 & 87.5 & 1,83885 & 0,18774 & 0,03524 & 0,006617 \\
15 & 63 & 93.75 & 1,79934 & 0,22725 & 0,05164 & 0,011735 \\
\hline & & & 2,02659 & $-0,00288$ & 0,291288 & 0,025200021 \\
\hline
\end{tabular}


Dengan memperhitungkan bahwa kecamatan rogojampi kabupaten banyuwangi berkembang dan termasuk kota kategori sedang yang berpenduduk diatas 200.000 jiwa.

Tabel 3. Perhitungan Curah Hujan Rencana

\begin{tabular}{ccccccc}
\hline ГR(Tahun) & $\mathrm{Pt}(\%)$ & $\mathrm{G}$ & $\mathrm{Sd}$ & $\mathrm{G} . \mathrm{Sd}$ & $\log \mathrm{XT}(\mathrm{mm})$ & $\mathrm{XT}(\mathrm{mm})$ \\
\hline 2 & 50 & 0.06312 & 0,1442 & 0,009101 & 2,035691 & 108,5652 \\
5 & 20 & 0.85464 & 0,1442 & 0,12323 & 2,14982 & 141,1952 \\
10 & 10 & 1.23352 & 0,1442 & 0,177877 & 2,204467 & 160,1278 \\
25 & 4 & 1.61266 & 0,1442 & 0,232545 & 2,259135 & 181,6080 \\
\hline
\end{tabular}

Sumber : Hasil Perhitungan

\section{Analisa Debit Air Kotor}

Berdasarkan data jumlah penduduk yang diperoleh dari kantor badan pengolahan statistik (BPS) kota sebagai berikut:

- Persamaan Geometrik

$$
P n=P o(1+r)^{n}
$$

Dimana : Po $=94.301$ jiwa

$$
\mathrm{r}=4,69 \%
$$

$\mathrm{n}=10$ tahun (2009-2019)

Maka : $\quad$ Pn $=$ Pox $\mathrm{e}^{\mathrm{rxn}}$

$$
\begin{aligned}
& =94.301 \text { jiwa } \times 2,71828183^{0.0469 \times 10} \\
& =150.731 \text { jiwa }
\end{aligned}
$$

Maka pertambahan penduduk pada tahun 2019 direncanakan \pm 56430 jiwa.

Contoh perhitungan saluran jalan gladag kanan sebagai berikut:

- Luas daerah pengaliran :0,09 km2

- Panjang saluran :630 meter

- Kemiringan dasar saluran(s)direncanakan :0,006

- Koefisien pengaliran:0,5133

- Curah hujan rancangan 2 tahun R24 :108,5652mm

- Debit limbah domestik :0,00467 m3/detik

- Koefisien kekasaran maning (n) :0,025

Berdasarkan data-data di atas tersebut dapat di hitung besarnya debit air hujan sebagai berikut:

- Perhitungn waktu konsentrasi direncanakan dengan menggunakan persamaan:

(suhardjono,1984:15

$$
T c=\left[\frac{T o+T d}{6 \hat{v}}\right]
$$

$\mathrm{Tc}=$ Waktu kosentrasi (jam)

$\mathrm{To}=$ Lama pegaliran air permukaan tanah ke saluran tedekat (menit)

$\mathrm{Td}=$ Lama pengaliran air dalam saluran

Besar To di dapat dari nomogram dengan memperhatikan kemiringan aliran,koefisiien kekasaran dan pajang saluran.

Besar Td tergantung pada panjang saluran,kemiringan saluran(semakin panjang saluran dengan emiringan landai,maka semakin lama waktu pengaliran atau $\mathrm{Td}$ semakin besar,demikian juga sebaliknya.

$$
T c=\left[\frac{43+7,24}{60}\right]
$$

$T c=0,84$

- Keepatan Aliran

$V 1=\frac{L}{T d}$

Dimana $\mathrm{L}=$ panjang Saluran

$\mathrm{Td}=$ Lama pengaliran air dalam saluran

$V 1=\frac{650}{7.24 \times 60}$

$V l=1,450 \mathrm{~m} / \mathrm{det}$

\section{- Intensitas Hujan}

Perhitungan inensitas curah hujan selama waktu konsentrasi direncanakan dengan menggunakan rumus Mononobe. Sebagai berikut: 


$$
I=\frac{R_{24}}{24} \times\left(\frac{24}{T c}\right)^{\frac{2}{3}}
$$

Diketahui :Hujan Harian Maksimum $\left(\mathrm{R}_{24}\right)$ 108,57

Waktu konsentrasi $=0,84$ jam

Maka : $I=\frac{108,57}{24} \times\left(\frac{24}{0.84}\right)^{\frac{2}{3}}$

$$
\begin{aligned}
& I=4,523 \times(28,57)^{\frac{2}{3}} \\
& I=42,35 \mathrm{~mm} / \mathrm{jam}
\end{aligned}
$$

- Perhitungan Debit Curah Air Hujan / Debit Banjir Rancangan (QCH)

Debit air hujan (QAh) dapat dicari dengan rumus rasional seperti dicontohkan pada salah satu ruas saluran Glaag kanan sebagai berikut :

$$
\begin{aligned}
\text { QA } & =0,278 \times C \times I \times A \\
& =0,278 \times 0,5133 \times 42,35 \times 0.09 \\
& =0.544 \mathrm{~m}^{3} / \text { det }
\end{aligned}
$$

- Debit Total (Qtotal) Untuk Ruas Saluran Gladag kanan

$$
\begin{aligned}
& \mathrm{QCH}=\mathrm{QLD}+\mathrm{QQCH} \\
& \mathrm{QCH}=0.00467+0.544=0.550
\end{aligned}
$$

- Debit Sistem (Qsistem) Untuk Ruas Saluran Gladag kanan

Qsistem $=0.555$

- Luas Penampang (A) untukmerencanakan Dimensi Saluran:

$$
\begin{aligned}
& A=\frac{Q \text { sistem }}{V 1} \\
& A=\frac{0.555}{1,42}=0,38
\end{aligned}
$$

- Setelah mendapatkan besarnya A0,38M2,Selanjutnya Direncanakan Dimensinya.

$$
\begin{aligned}
& \mathrm{b}=1 \mathrm{~m} \\
& \mathrm{~h}=0,9 \mathrm{~m} \\
& \mathrm{~A}=\mathrm{b} \times \mathrm{h} \\
& \mathrm{P}=\mathrm{b}+(2 \times \mathrm{h}) \\
& \mathrm{P}=\mathrm{p}+(2 \times 0.9)
\end{aligned}
$$

$\mathrm{P}=1,0+(2 \times 0,9)$

$\mathrm{P}=2,80$ meter

- $\quad$ Dicari besar jari jari hidrolis $(\mathrm{R})$

$\mathrm{R}=\mathrm{A} / \mathrm{P}$

$\mathrm{R}=0,9 / 2,8=0,32$ meter

- Dicari Besar V2

$$
V 2=\frac{1}{n} \times R^{\frac{2}{3}} x S \frac{1}{2}
$$

Dimana $n=$ koefisien kekasaran maning $=0,25$

$\mathrm{S}=$ Kemiringan dasar saluran

$\mathrm{R}=$ jari jari hidrolis

$$
V 2=\frac{1}{0,025} \times 0,32^{\frac{2}{3}} \times 0,006 \frac{1}{2}
$$

$\mathrm{V} 2=1,450$ meter

Di control $\mathrm{V} 1=\mathrm{V} 2$

$1,450=1,450$

Jika ternyata V2 tidak sama dengan V1,maka besarnya Td di ats harus di coba kembali

- Ditentukan tinggi jagaan (w)

$$
\begin{aligned}
\mathrm{W} & =30 \% \times \mathrm{h} \\
& =30 \% \times 0,9 \\
\mathrm{~W} & =0,30 \text { meter }
\end{aligned}
$$

\section{Perencanaan bangunan gorong-gorong}

Contoh perhitungan bangunan gorong-gorong

- Menentukan debit air yang masuk

- Debit Saluran yang masuk :0,649m3/detik

- Panjang Gorong-Gorong:7 meter

- Kecepatan air saluran :1,10meter

- Elevasi dasar hulu $\quad$ :99.98

- Elevasi dasar Hilir $\quad$ :99,88

- Kemiringn dasar saluran(S) :0,006

- $\quad$ Dicari Luas Bangunan $(A)$

Dicoba $Z=0,1$ meter

Qaktual $=\mu \times A \sqrt{2 x g x Z}$

Dimana $\mu=0,8$ Untuk penampang segiempat.

$$
\begin{aligned}
A & =\frac{Q}{0,8 \sqrt{2 x g x Z}} \\
A & =\frac{0,649}{0,8 \sqrt{2 \times 9,81 \times 0,1}} \quad A=0,579 \mathrm{~m} 2
\end{aligned}
$$


- Merencanakan dimensi saluran

$$
\begin{aligned}
& \mathrm{h}=0,4 \mathrm{~m} \\
& \mathrm{~b}=0,4 \\
& \mathrm{p}=0,4+(2 \times 0,4)=1,2 \mathrm{~m} 2
\end{aligned}
$$

- Mencari jari-jari hidrolik(R)

$$
\begin{aligned}
& \mathrm{R}=\mathrm{A} / \mathrm{P} \\
& \mathrm{R}=0,579 / 1,2 \\
& \mathrm{R}=0,483
\end{aligned}
$$

- Menentukan besar Qaktual (Gorong-gorong dengan panjang $<20$ meter)

Qaktual $=\mu \times A \sqrt{2 x g x Z}$

Qaktual $=0,8 \times 0,579 \sqrt{2 x 9,81 x 0,1}$

Qaktual $=0,648$

Syarat : Qrencana < Qaktual

$=0,579<0,648$. ..(OK)

- Kecepatan rencana(Vrencana)

Dicoba : 1,200 m/detik

Kecepatan aliran gorong-gorong (Vrencana) antara 1-2X Kecepatan awal

- Mencari kehilangan energi (Ah)

Kehilangan energi masuk :

Ahmasuk $=0,5 \times\left(\frac{\text { Vawal }- \text { Vrencana }}{2 x g}\right)^{2}$

Ahmasuk $=0,5 \times\left(\frac{1,91-2,9}{2 x 9,81}\right)^{2}$

Ahmasuk $=0,0012$ meter

Kehilangan energi keluar:

Ahkeluar $=1 \times\left(\frac{\text { Vawal }- \text { Vrencana }}{2 x g}\right)^{2}$

Ahkeluar $=1 \times\left(\frac{1,91-2,9}{2 \times 9,81}\right)^{2}$

Ahkeluar $=0,0024$ meter

Kehialngan akibat gesekan(Ahf)

$\Delta h f=\frac{v^{2} \times L}{c^{2} \times R}$

$$
\Delta h f=\frac{v^{2} \times L}{\left(K \times R^{1 / 6}\right)^{2} \times R}
$$

- $\quad$ menentukan tinggi energy

$\mathrm{Z}=$ Ahmasuk + Ahkeluar + Ahgesekan

$\mathrm{Z}=0,0012+0.0024+0,01045$

$\mathrm{Z}=0,01405$
- Tinggi jagaan

$\mathrm{f}=0,3 \times \mathrm{h}$

$\mathrm{f}=0,3 \times 0,4$

$\mathrm{f}=0,060$ meter

\section{KESIMPULAN DAN SARAN}

\section{Kesimpulan}

Berdasarkan rumusan masalah dan hasil analisa kapasitas saluran drainase di kecamatan rogojampi kabupaten banyuwaangi maka dapat diambil kesimpulan sebagai berikut ;

- Besar curah hujan rancangan kala ulang 2 tahun adalah sebesar 108,565 mm.

- Besar debit banjir rancangan terbesar kala ulang 2 tahun adalah sebesar $1.852 \mathrm{~m} 3 \mathrm{dtk}$.

- Jumlah ruas saluran yang mencukupi menampung debit air sebanyak 52 saluran,yang mengalami perbaikan sebanyak 12 saluran dan saluran baru sebanyak 15 saluran.

\section{Saran}

- Dari hasil studi ini, diharapkan ada tindak lanjut yang nyata dari Pemerintah Daerah, untuk mengurangi area genangan akibat banjir di kecamatan rogojampi kabupaten banyuwangi

- Mempertahankan taman kota untuk menambah daya filtrasi tanah, sehingga dapat mengurangi debit aliran permukaan (run off) akibat hujan.

- Mengadakan sosialisasi kepada masyrakat untuk menjaga kelestarian lingkungan, untuk menjaga fungsi saluran drainase.

\section{DAFTAR PUSTAKA}

Anonim. Drainage Improvement Work in Surabaya Urban Development Project, Channel Improvement of Gunungsari Drainage Channel and Construction of Related River Structures.

Chow, Ven Te. 1992. Hidrolika Saluran Terbuka, Jakarta : Airlangga.

Joetata Hadihardjaja, 1997. Drainase Perkotaan. Gunadarma, Jakarta.

MP, Suhardjono. 1984. Drainase Kota, Malang : Universitas Brawijaya

Sosrodarsono, Suyono, Ir. 1999. Hidrologi untuk Pengairan, Jakarta : PT. Pradnya Paramita. 
Soemarto, CD. 1987. Hidrologi Teknik, Surabaya : Usaha Nasional.

Subarkah, Iman, Ir. 1980. Hidrologi untuk Perencanaan Bangunan Air, Bandung : Idea.Dharma

Suripin, Dr. Ir. M.Eng. 2003. Sistem Drainase Perkotaan yang Berkelanjutan, Yogyakarta 